\title{
Ações do Profissional de Psicologia no Centro de Referência da Assistência Social
}

Actions of Psychology Professional at the Reference Center of Social Assistance

Acciones del Profesional de Psicología en el

Centro de Referencia de Asistencia Social

\section{Orlando Júnior Viana Macêdo}

Universidade Federal da Paraíba

Maria de Fátima Pereira Alberto

Universidade Federal de Pernambuco

Denise Pereira dos Santos,

Gabriel Pereira de Souza \&

Vinicius Suares de Oliveira

Universidade Federal da Paraíba

http://dx.doi.org/10.1590/1982-3703001632013 
Resumo: Neste artigo, discutem-se as ações dos profissionais de Psicologia nos Centros de Referência de Assistência Social (CRAS). Trabalhou-se com sete profissionais de Barbalha, Crato e Juazeiro do Norte, Ceará. Utilizou-se de entrevista semiestruturada, que contemplou dados biosociodemográficos; dificuldades enfrentadas; formação acadêmica e atividades realizadas. Os dados foram analisados por meio de análise de conteúdo. As falas denotaram que há dificuldades decorrentes tanto das condições de trabalho oferecidas quanto da formação acadêmica. A formação dá suporte para uma atuação clínica individualizante. A prática gira em torno do acolhimento e atendimento psicológico. Percebe-se atuação com alcance limitado no que concerne ao desenvolvimento da autonomia e da efetivação dos direitos dos usuários, sinalizando-se para importância de os profissionais recorrerem a versões de Psicologia mais politizadas e comprometidas com os sujeitos em condição de vulnerabilidade social.

Palavras-chave: Atuação (Psicologia). Psicologia.

Abstract: This study discusses the actions of psychology professionals at the Reference Center of Social Assistance. Seven professionals were interviewed from the cities of Barbalha, Crato, and Juazeiro do Norte, in Ceará State. A semi-structured interview protocol was used considering the following aspects: bio-socio-demographic data, difficulties faced, academic formation, activities accomplished, and psychology's contribution to users. Content analysis was used to analyze the data. The transcripts denote the following: challenges due to the work conditions and academic formation. This formation only provides support to an individualizing clinical practice; practice is limited to welcoming and psychological care. It is possible to find practices with limited reach with regard to autonomy and execution of users' rights development, which demonstrates how important it is for professionals to use more standardized and engaging psychology versions with clients in social vulnerability conditions.

Keywords: Acting out; Psychology

Resumen: El artículo discute las acciones de los profesionales de psicología en los Centros de Referencia de Asistencia Social. Se trabajó con siete profesionales de Barbalha, Crato y Juazeiro do Norte. Las entrevistas semi-estructuradas abordaron: datos biosociodemográficos, dificultades enfrentadas, formación académica, actividades realizadas, y contribución de la psicología para los usuarios. Los datos fueron analizados mediante el análisis de contenido. Los discursos denotaron que: existen dificultades derivadas tanto de las condiciones de trabajo ofrecidas como de la formación académica; esta formación favorece una actuación clínica individualizante; la práctica gira en torno al acogimiento y la atención psicológica. La actuación es limitada en cuanto al desarrollo de la autonomía y la realización de los derechos de los usuarios, mostrando la importancia que los profesionales utilicen versiones de Psicología más politizadas y comprometidas con los sujetos en condición de vulnerabilidad social.

Palabras-clave: Actuación (Psicología). Psicología. 


\section{Introdução}

O presente artigo tem como objetivo identificar as ações dos profissionais de Psicologia em sua atuação nos Centros de Referência de Assistência Social (CRAS). Para isso, foi realizada uma pesquisa com psicólogos inseridos em CRAS de três municípios do interior do Ceará.

O CRAS, de acordo com o Ministério do Desenvolvimento Social e Combate à Fome (MDS), é uma unidade pública estatal, territorializada, que deve atuar como a principal porta de entrada do Sistema Único de Assistência Social - SUAS (Brasil, 2009a). Na atual Política Nacional de Assistência Social, o SUAS sistematiza duas grandes estruturas interligadas: a Proteção Social Especial (PSE) e a Proteção Social Básica (PSB). A primeira é destinada a famílias e indivíduos que se encontram em situações de violação dos direitos. Já a Proteção Social Básica está voltada para a prevenção de situações de risco, sendo esse último nível de proteção destinado à população que vive em situação de vulnerabilidade social.

O CRAS, de acordo com a Tipificação Nacional dos Serviços Socioassistenciais, é uma unidade da Proteção Social Básica que prevê o desenvolvimento dos Serviços de Proteção e Atendimento Integral à Família (PAIF), de Convivência e Fortalecimento de Vínculos e de Proteção Social Básica no domicílio para pessoas com deficiência e idosas. O PAIF consiste em uma proposta de trabalho social com famílias, de caráter continuado, com a finalidade de fortalecer a função protetiva das famílias, de prevenir a ruptura dos seus vínculos, de promover seu acesso e usufruto de direitos e de contribuir na melhoria de sua qualidade de vida. O Serviço de Convivência e Fortalecimento de Vínculos consiste em ações realizadas em grupos, organizadas a partir de percursos, de modo a garantir aquisições progressivas aos seus usuários, de acordo com o seu ciclo de vida, a fim de complementar o trabalho social com famílias e prevenir a ocorrência de situações de risco social. O Serviço de Proteção Social Básica no domicílio para pessoas com deficiência e idosas tem por finalidade a prevenção dos agravos que possam provocar o rompimento de vínculos familiares e sociais dos usuários (Brasil, 2009b).

De acordo com a Política Nacional de Assistência Social - PNAS (Brasil, 2004), vulnerabilidade envolve situações decorrentes de perda ou fragilidade de vínculos de afetividade, pertencimento e sociabilidade; de identidades estigmatizadas em termos étnico, cultural e sexual; de desvantagem pessoal resultante de deficiência; de exclusão pela pobreza e/ou no acesso às demais Políticas Públicas; de uso abusivo de substâncias psicoativas; de diferentes formas de violência advindas do núcleo familiar, grupos e indivíduos; de inserção precária ou de não inserção no mercado formal e informal; de estratégias alternativas e diferenciadas que podem representar risco pessoal e social.

O CRAS deve concentrar-se em locais onde há maiores índices de vulnerabilidade social, uma vez que é a existência dessa unidade que configura a Proteção Social Básica nos municípios e no Distrito Federal. É responsabilidade dos profissionais de nível superior que compõem a equipe técnica do CRAS desenvolver programas e projetos que visem ao acolhimento e promovam convivência e socialização, conforme a vulnerabilidade em foco, por meio de intervenções que fortaleçam a função protetiva da família e potencializem protagonismo e autonomia das famílias e comunidades (Brasil, 2012).

Os programas e projetos do CRAS se voltam prioritariamente ao convívio familiar e comunitário, mirando os indivíduos em seu contexto e dinâmica familiar, compreendendo o conceito de família no sentido de núcleos de pertença, que promovem vínculos afetivos e identitários, além de mediação dos membros com outras instituições, definidos como "conjunto de pessoas unidas devido à ascendência, descendência, afinidade e/ou solidariedade" (Brasil, 2012, p. 10). Para isso, deve considerar os diferentes arranjos familiares, com vistas 
ao protagonismo dos membros no fortalecimento dos referidos vínculos.

De acordo com o Ministério do Desenvolvimento Social e Combate à Fome (2005), as atividades a serem desenvolvidas são voltadas para a inclusão produtiva, grupos de convivência, programas de protagonismo juvenil e serviços para crianças de zero a seis anos, para garantia dos direitos de crianças e adolescentes, programas de formação para o trabalho, entre outros.

O Conselho Federal de Psicologia (CFP) enfatiza que a atuação do profissional de Psicologia no CRAS deve priorizar práticas que promovam "integração entre vivências, leitura crítica da realidade e ação criativa e transformadora, a fim de que as pessoas reconheçam-se e se movimentem na condição de co-construtoras de si e dos seus contextos social, comunitário e familiar" (Conselho Federal de Psicologia, 2008, p. 34). Enfatiza ainda que, ante as premissas do trabalho social no SUAS, não há espaço para a realização de atendimento psicoterápico individual, devendo ser este referenciado para as unidades básicas de saúde e serviços de psicoterapia disponíveis nos municípios.

Dessa forma, percebe-se que, teoricamente, se passa de uma visão assistencialista e filantrópica para uma visão da proteção social, enquanto um direito social, dirigida a todos os que dela necessitam, voltada à dimensão do desenvolvimento das potencialidades coletivas, comunitárias e familiares, compreendendo os indivíduos em suas relações de pertença e socialização, e também em seu papel de construtores e protagonistas na realidade em que se inserem, conforme sinalizam Cruz e Guareshi (2009).

Levando-se em consideração os marcos legais do SUAS e as referências técnicas do CFP, é a partir desses princípios de atuação geral que devem estar norteadas as ações do profissional de Psicologia no CRAS. Nesse sentido, as ações devem ser pautadas nas necessidades e experiências dos usuários, não no sentido de se proceder a classificações, mas, sim, de se compreender o processo histórico em que se constituem de forma a ressignificar o papel dos sujeitos na direção da autonomia e participação nos processos políticos e na resolução das dificuldades vivenciadas.

Essa atuação no CRAS tem sido abordada sob diferentes perspectivas em alguns estudos, a saber: Cruz e Guareshi (2009), chamando atenção para o predomínio de concepções e práticas avaliativas e adaptacionistas; e Alberto, Freire, Leite e Gouveia, (2014), Ansara e Dantas (2010), Macêdo (2014), Macedo e Dimenstein (2012), Raichelis (2010) e Yamamoto e Oliveira (2010), entre outros, têm se debruçado sobre os limites institucionais e políticos da Assistência Social brasileira, diante do atual cenário de exclusão social e violência estrutural, que podem comprometer processos de desenvolvimento de autonomia e fortalecimento dos usuários das políticas de Assistência Social. Sobretudo quando se leva em consideração falta de recursos e de suporte organizacional do serviço, falta de equipe consolidada e capacitada, desarticulação da rede socioassistencial e conhecimento reduzido dos usuários e funcionários quanto ao SUAS (Ribeiro, 2010).

Tais limites podem fazer com que tal política, como chama atenção Netto (2011), apenas procure administrar as expressões da "questão social" de forma a atender às demandas da ordem monopólica, operando como um vigoroso suporte da ordem sociopolítica capitalista. No entanto, Netto (2011) acrescenta que o Estado, ao buscar legitimação política através do jogo democrático, é permeável a demandas das classes subalternas, que podem fazer incidir nele seus interesses e suas reivindicações imediatas. O que faz com que as políticas públicas tanto estejam voltadas para o controle ou dominação, quanto para o atendimento de determinadas demandas dos setores subalternos da sociedade, sendo as mesmas um terreno de conflitos, constituídas como respostas tanto às exigências da ordem monopólica, quanto ao protagonismo proletário.

Outros estudos se debruçam sobre a atuação do profissional de Psicologia no CRAS 
com foco em contextos específicos. Cruz (2009), abordando tal temática no estado de Sergipe, constatou que a formação oferecida na academia não fornece subsídio necessário aos profissionais de Psicologia. Andrade (2009) e Andrade e Romagnoli (2010), debruçando-se sobre a realidade do interior de Minas Gerais, perceberam a necessidade de intervenções psicológicas para além da psicologização e do modelo tradicional desse fazer.

Macedo (2007) e Macedo e Dimenstein (2009), analisando as práticas de cuidado de psicólogos que atuam no campo das políticas sociais da cidade de Natal, no Rio Grande do Norte, especificamente no âmbito da Saúde (SUS) e Assistência Social (SUAS), identificaram, entre outros aspectos, uma precarização das condições de trabalho (questão salarial, falta de estrutura, de capacitação e autonomia para desenvolvimento das atividades) e predomínio de realização da escuta e encaminhamento para a realização de atividades. Também na cidade de Natal, Oliveira, Dantas, Solon e Amorim (2011) identificaram elevado número de profissionais de Psicologia que executam a clínica tradicional no CRAS.

Nery (2009), em seu estudo, aborda tanto Minas Gerais quanto São Paulo e, a partir das constatações, destaca relevância da ampliação dos aportes teórico-metodológicos para uma leitura crítica da realidade social e evidencia os precários vínculos e condições de trabalho dos profissionais de Psicologia no CRAS. Fernandes, Joca, Alencar e Albuquerque (2008) discutem a atuação desses profissionais nos CRAS da cidade de João Pessoa-PB e chamam atenção para a discrepância entre formação acadêmica e demandas das Políticas Públicas. E Fontenele (2008), enfocando o contexto da capital do Ceará, Fortaleza, e cidades circunvizinhas, identificou uma formação acadêmica que não dá subsídios para atuação em comunidade e predomínio de uma atuação pautada no modelo clínico, embora alguns profissionais apresentassem alternativas baseadas no compromisso social e na Psicologia Social Comunitária (PSC).
Outros estudos abordam aspectos que perpassam essa atuação dos profissionais de Psicologia no contexto do CRAS, a saber: Ximenes, Paula e Barros (2009) - buscando traçar diálogos teórico-metodológicos entre a práxis de Psicologia Comunitária e a atuação no CRAS, apontam as contribuições da Psicologia Comunitária para a leitura e a efetivação de trabalhos coletivos no território de vida das famílias; Silva, Silva, Brustolin e Pessini (2011), refletindo sobre as consequências do assistencialismo nas práticas psicológicas no CRAS, a partir dos princípios teóricos da Psicologia Comunitária, chamam a atenção para a necessidade de constante reflexão sobre atuação do profissional de Psicologia nesse contexto; Mota e Goto (2009) e Soares, Susin e Warpechowski (2009), apresentando as contribuições da clínica ampliada na Política de Assistência Social; Bock (2009), chama a atenção para a necessidade de a Psicologia consolidar um compromisso social, um trabalho em nome dos direitos humanos e pelo fim das desigualdades sociais; e Alberto et al. (2008), analisando o trabalho de psicólogos junto a crianças e adolescentes em situação de risco, chamam a atenção para o fato de sobressair uma atuação fundamentada num modelo clínico e individual, faltando, tanto às instituições, quanto aos psicólogos, maior conhecimento do papel desses profissionais junto às Políticas Públicas direcionadas a crianças e adolescentes em situação de risco.

Para promover a prática no CRAS, o Conselho Federal de Psicologia (2008) afirma que os profissionais de Psicologia devem atuar comprometidos com a promoção de direitos, de cidadania, da saúde, com a promoção da vida, tomando como referenciais os aportes teórico-práticos provenientes da Psicologia do Desenvolvimento, da Psicologia Institucional, da Psicologia Social e da PSC. Dessa forma, considera-se que os referenciamentos e marcos legais da Política de Assistência Social prescrevem um modelo de atuação para os profissionais de Psicologia, que está contemplada pelo que propõe a PSC, fazendo dessa versão de Psicologia Social uma importante referência teórica e metodológica para a atuação dos profissionais de Psicologia no CRAS, pelo que a PSC oferece em consonância com a realidade concreta dos usuários 
dessa política. Haja vista a defesa de uma atuação implicada por parte do profissional de Psicologia, buscando-se uma transformação social pautada por preceitos eticamente humanos e solidários (Góis, 2008).

No presente estudo, entende-se a Psicologia Social Comunitária como uma área da Psicologia Social orientada por uma práxis libertadora, a partir das próprias condições (atuais e potenciais) de desenvolvimento da comunidade e de seus moradores (Góis, 2008). Nesse sentido, para esse autor, o fundamental é a compreensão do modo de vida da comunidade e a realização de seus potenciais de desenvolvimento pessoal e social. Tal versão de Psicologia Social se constituiu a partir das bases: Educação Popular, ensejada por Paulo Freire, e das vertentes teóricas tanto de Silvia Lane, quanto de Martin Baró, a partir de uma interlocução entre a perspectiva histórico-cultural, do russo Vigotski, e da reconceituação da Psicologia Social.

Dessa forma, a PSC consiste em uma práxis em Psicologia, caracterizada pela ênfase no caráter histórico; pela análise da realidade social como orientadora fundamental dos estudos psicológicos; pelo combate ao objetivismo; pelo reconhecimento do caráter ativo dos seres humanos como produtores da história; pela preocupação em incluir no estudo psicológico o ponto de vista dos oprimidos, compreendidos como sujeitos epistêmicos; pela consideração de que o conflito é parte da ação humana; pelo reconhecimento da importância da ideologia como fenômeno psicológico; pela incorporação de uma concepção dinâmica e dialética dos seres humanos; pelo fomento da autonomia e emancipação social (Nepomuceno, Ximenes, Cidade, Mendonça, \& Soares, 2008).

A partir disso, aponta-se a necessidade de se pensar uma atuação da Psicologia no CRAS em consonância com as reais necessidades dos sujeitos em condição de vulnerabilidade social. No entanto, por um lado, tem-se uma formação acadêmica técnica e apolítica e, por outro lado, um processo de desmantelamento das políticas do Sistema de Proteção Social, que repercute no modo de trabalho dos profissionais de Psicologia em tal contexto. Isso faz com que os profissionais se deparem com uma elevada carga horária e baixa remuneração, alta rotatividade dos técnicos, que fragiliza os laços com usuários e dificulta trabalho em equipe, além das condições inadequadas de trabalho na unidade, haja vista a falta de recursos para o desenvolvimento das atividades (Macedo, 2007).

Diante dessas limitações impostas pelas Políticas Públicas, de uma formação acadêmica que não dá subsídios para uma atuação nesse contexto e das diretrizes e marcos legais da Política de Assistência Social, que prescrevem uma atuação pautada num modelo de assistência como um direito social, configurou-se um desejo que nos impeliu à ação de pesquisa, com o propósito de identificar como se têm dado as ações dos profissionais de Psicologia nos Centros de Referência da Assistência Social.

\section{Método}

\section{Participantes}

O presente estudo foi realizado contemplando sete profissionais de Psicologia que atuavam no CRAS, por meio do Serviço de Proteção e Atendimento Integral à Família - PAIF e do Serviço de Convivência e Fortalecimento de Vínculo. Seis eram do sexo feminino e um do sexo masculino. Dos participantes do estudo, um trabalhava na cidade de Barbalha, três em Juazeiro do Norte e três em Crato. Essas cidades fazem parte da Região Metropolitana do Cariri, que está geograficamente situada no sul do Ceará, distando, em média, $612 \mathrm{Km}$ de Fortaleza. A principal característica dessa região é o comércio, bastante dinâmico, influenciado pela indústria calçadista e, sobremaneira, pelas gigantescas romarias em função do que o Padre Cícero representa no imaginário popular.

\section{Instrumento}

Utilizou-se de entrevista semiestruturada, realizada individualmente. Esta contemplava os seguintes aspectos: dados biosociodemográficos; 
dificuldades enfrentadas no trabalho; formação acadêmica; e atividades realizadas.

Procedimentos de coleta e análise dos dados

Os participantes do estudo foram selecionados a partir do critério de conveniência, e o número de profissionais de Psicologia foi definido a partir do critério de saturação (Fontanella, Ricas \& Turato, 2008). Ao longo de todo o estudo, cujos dados foram coletados em dezembro de 2011, cumpriram-se todos os princípios éticos recomendados na pesquisa com seres humanos, em acordo com a Resolução ${ }^{\circ}$ 196/96, do Conselho Nacional de Saúde.

Os sujeitos foram abordados no próprio ambiente de trabalho, após autorização prévia do coordenador da instituição e agendamento, levando-se em consideração a disponibilidade do profissional. Com entrevistas gravadas, estas foram transcritas fielmente às falas dos entrevistados e analisadas de acordo com a análise de conteúdo, mais especificamente, por meio da técnica de análise temática (Bardin, 2010). Optou-se pela técnica de validação por dois juízes, ambos previamente treinados para tal. Dessa forma, foi realizada uma leitura flutuante de todo o material transcrito e impresso, para se ter uma ideia do conteúdo como um todo das falas dos sujeitos. Posteriormente foi realizada a tabulação, que consistiu numa agregação das temáticas semelhantes.

A partir das temáticas Dificuldades para atuação no CRAS, Contribuição da formação acadêmica e Atividades realizadas, foi realizada uma codificação, transformação dos dados brutos do texto, de forma a possibilitar atingir-se uma representação do conteúdo, esclarecendo-se o analista acerca das características do texto. Da codificação, emergiram as categorias representativas dos núcleos de sentido. As categorias serão apresentadas e discutidas, seguindo-se a ordem das mais representativas às menos representativas.

\section{Resultados e Discussão}

O tempo de formação dos sete profissionais de Psicologia que participaram do presente estudo variou de dez anos a seis meses. E o tempo de atuação no CRAS variou de cinco anos a dois meses. A partir das falas, percebe-se consonância em relação às dificuldades relatadas pelos profissionais de Psicologia, o que denota que mesmo os profissionais formados recentemente não se sentem aptos para atuarem nessa Política Pública de Proteção Social do âmbito da Assistência Social. O tempo de atuação no CRAS apresentou-se, também, como outra variável que pouco interfere nas dificuldades que os profissionais enfrentam, o que denota que, mesmo vivenciando a experiência de atuar no CRAS, com o passar do tempo, os profissionais de Psicologia não têm encontrado estratégias eficazes para lidar com as dificuldades com as quais se deparam.

Do total de participantes, seis exerciam outra atividade além do CRAS, sendo que essa outra atuação se dava em outras Políticas Públicas, seja da Educação ou da Assistência Social, ou na iniciativa privada, seja no âmbito da educação ou em consultório clínico. Percebe-se que esses profissionais tentam dividir seu tempo entre a atuação no CRAS e em outros espaços, o que, segundo Macedo (2007), se justifica pela necessidade de se complementar a renda mensal, o que pode comprometer a qualidade das ações desenvolvidas, haja vista limitação de tempo para planejamento de atividades bem como dificuldades de intervenções em parceria com outros profissionais de nível superior que compõem a equipe do CRAS.

Dos profissionais de Psicologia entrevistados, cinco tinham formação complementar, sendo essas especializações em Administração Hospitalar, Docência do Ensino Superior, Psicopedagogia e Saúde da Família. Percebe-se que esses profissionais buscam qualificar-se por meio de uma formação complementar. No entanto, como chama atenção Cruz (2009), tais buscas por especializações têm acontecido de forma desordenada, pois faltam foco e clareza quanto aos saberes complementares que eles precisarão para consubstanciar sua vida profissional. 
Além dos aspectos biosociodemográficos, as falas dos profissionais de Psicologia versaram sobre os temas: Dificuldades para atuação no CRAS; Contribuição da formação acadêmica em Psicologia para atuação no CRAS e Atividades realizadas em uma semana típica de trabalho. A partir dessas temáticas, foram agrupadas as categorias representativas das falas dos sujeitos.

\section{Dificuldades para atuação no CRAS}

Quando os profissionais de Psicologia foram questionados acerca das dificuldades que enfrentavam no cotidiano de suas ações como profissionais, as falas revelaram dificuldades tanto de ordem pessoal, relacionadas a uma formação acadêmica inadequada, frente à proposta do CRAS e às demandas dos usuários, quanto de ordem institucional. Essas dificuldades institucionais são relacionadas a condições inadequadas para a realização do trabalho pelo profissional de Psicologia no CRAS.

No que diz respeito à formação acadêmica em Psicologia, as falas revelaram que os profissionais consideram que ela não prepara para atuar no CRAS, uma vez que se depararam, ao longo da graduação, com uma formação voltada para uma atuação focada numa perspectiva individualizante, com viés clínico e com disciplinas puramente teóricas, o que fez com que esses profissionais só viessem conhecer o CRAS quando passaram a trabalhar em tal política. Tais achados corroboram as constatações de Cruz e Guareshi (2009), Fernandes et al. (2008), Silva et al. (2011) e Yamamoto e Oliveira (2010), acerca da discrepância entre formação acadêmica e demandas com que o profissional se depara em sua atuação profissional. O depoimento da entrevistada dois, que segue, representa como essa questão é percebida pelos profissionais de Psicologia: "[...] a minha formação foi muito voltada pra um lado e agora eu estou trabalhando noutro, eu estou tendo que estudar tudo de novo".

Tais dados podem estar sinalizando que a formação acadêmica não contempla aspectos pertinentes à realidade e às demandas que o mercado exige de um profissional para atuar no CRAS, por não incorporar elementos que façam a mediação entre a existência desses espaços institucionais e formação acadêmica, de forma a contemplar as demandas de atuação profissional numa perspectiva psicossocial, que promova autonomia e efetive os direitos dos usuários, garantindo cidadania.

No que se refere à relação entre formação acadêmica e demandas dos usuários, as falas revelaram que os profissionais sentiram e sentem dificuldades na sua atuação profissional por lidarem com grande número de famílias atendidas pelo CRAS, bem como com questões de ordem mais social, como o fenômeno da violência e da dependência química, tão presentes nas comunidades referenciadas pelo CRAS. O social refere-se aqui a questões que emergem como resultantes do processo histórico do capitalismo, como "manifestação no cotidiano da vida social da contradição capital-trabalho" (Yamamoto, 2007, p. 31). O que demanda, portanto, uma ampliação da dimensão política desta atuação dos profissionais e requer o desenvolvimento, no campo acadêmico, de outras possibilidades teórico-técnicas na Psicologia, vinculadas a um projeto ético-político (Yamamoto, 2012).

Essa dificuldade por parte dos profissionais de Psicologia, de lidar com tais questões, pode ser resquício de uma formação acadêmica que historicamente vinha priorizando outros segmentos da sociedade por meio de uma intervenção individualizante em consultórios particulares (Ansara \& Dantas, 2010; Lima, 2012; Silva et al., 2011). Isso dificultaria uma atuação nas Políticas Públicas de Proteção Social, no âmbito da Assistência Social, em uma perspectiva promotora de autonomia e de efetivação dos direitos dos usuários.

Para que os profissionais de Psicologia tenham condições de atuar de forma a promover autonomia e efetivar direitos dos usuários, faz-se necessário que os mesmos tenham acesso, ao longo da graduação, a modelos outros de Psicologia, que superem perspectivas individualizantes e descontextualizadas de análise e intervenção sobre a realidade. Dessa 
forma, sinaliza-se com uma possibilidade de se recorrer a ferramentas e técnicas oriundas de versões mais politizadas e comprometidas com os sujeitos em condição de vulnerabilidade social.

Dentre algumas possibilidades de Psicologia mais politizadas e comprometidas socialmente, destaca-se, no presente estudo, a Psicologia Social Comunitária, cujas possibilidades metodológicas sinalizam para importância de: identificação conjunta de necessidades e potencialidades da comunidade atendida; aportes participativos, como a observação-participante, a pesquisa-participante e a ação-participante; acompanhamento de grupos comunitários; entrevistas individuais e/ou coletivas; participação em atividades da comunidade e registros de acontecimentos e/ou episódios significativos em diários de campo; visitas domiciliares; conversas informais com moradores, contatos com lideranças formais e informais e levantamento de documentos e de outras produções locais; e acompanhamento de grupos (Góis, 2008; Ximenes et al., 2009).

A dificuldade para atuação que teve como temática enunciadora a categoria condições inadequadas para o trabalho revela que os profissionais de Psicologia vêm se deparando com quantidade limitada de carros para as visitas domiciliares, inadequação da estrutura física do CRAS e escassez de material para realização das atividades. Essa falta de recursos para desenvolvimento de atividade é explicada por Macedo (2007) como sendo reflexo de uma precarização da política e do desmantelamento do Sistema de Proteção Social. Andrade e Romagnoli (2010) e Yamamoto e Oliveira (2010) também chamam atenção para essa dificuldade de suporte para os profissionais do CRAS, articulando-a às questões políticas.

O depoimento da psicóloga que segue abaixo dá conta dessas dificuldades: "[...] É, primeiro a questão do material é, como é que a gente chama? É, do material mesmo pra trabalhar, né [sic]? Material pros grupos [...] não tem. Precisamos de impressão, tem impressora, mas não tem o toner". Percebe-se, dessa forma, que os profissionais de Psicologia, no âmbito de trabalho no CRAS, se deparam com determinadas condições desfavoráveis à sua atuação profissional. Essa dificuldade, como sinalizado anteriormente, é somada a uma formação acadêmica que não prepara o profissional de Psicologia para lidar com essas questões, haja vista a ênfase em perspectivas intimistas, individualizantes e elitistas, em detrimento de uma formação acadêmica que desenvolva profissionais capazes de analisar criticamente as políticas em voga, capazes de se mobilizar na tentativa de superar limitações impostas pela atual realidade das Políticas de Assistência Social e propor alterações ou políticas que contemplem, de fato, os anseios das comunidades e dos grupos em condição de vulnerabilidade social e que possam pôr em prática ações focadas em sujeitos vistos como atores, protagonistas.

Contribuição da formação acadêmica em Psicologia para atuação no CRAS

As falas dos profissionais de Psicologia revelaram uma categoria representativa acerca da contribuição da formação acadêmica para sua atuação no CRAS, a saber: técnicas de uma clínica individualizante. Os entrevistados revelaram que a formação acadêmica subsidia uma atuação focada no indivíduo, haja vista a ênfase, por parte dos profissionais de Psicologia, na escuta e atendimento psicológico.

O depoimento da entrevista dois representa bem a forma com que a formação acadêmica contribuiu para a atuação dos profissionais de Psicologia no CRAS:

[...] a minha universidade tem um viés muito psicanalítico, que são [sic!] muito clínico, muito voltado para atendimento [...] então o que é que acontece? [...] o que é que esses conhecimentos estão me trazendo hoje em dia pra cá? Muito! Principalmente pelo lado da escuta.

Os depoimentos dos profissionais de Psicologia revelaram que a formação acadêmica deu subsídios para atuação no CRAS por 
meio da clínica, colocada essa não como um método, mas, sim, como sinônimo de "tecnologias psicoterapêuticas" (Silva, 2011). Tal autor nos ajuda a entender essa questão quando considera que vigora na categoria dos profissionais de Psicologia uma grosseira redução da clínica, enquanto método, em mera expressão particular do exercício de uma das tecnologias psicoterapêuticas numa perspectiva individualizante.

Sobre atuação focada no indivíduo como resultado de uma contribuição da formação acadêmica, Bock (2009) considera que os profissionais aprendem a atuar, de certa forma, em determinada situação, não desenvolvendo a capacidade de lidar com o desconhecido, o que engessa as práticas da Psicologia. Sobre esse limitado repertório de atuação dos profissionais de Psicologia e chamando atenção para necessidade de uma atuação pautada numa perspectiva de efetivação dos direitos, Alberto et al. (2008) consideram que a psicoterapia não pode ser o modo por excelência da atuação do profissional de Psicologia. Deve esse profissional ocupar um espaço político e público de forma que possa compreender os processos de subjetivação tais como se produzem na sociedade brasileira por meio de um diálogo com as referências teóricas conectadas a essa realidade. Como salienta Freitas (1998), a visão de homem e a de mundo, assumidas e vividas pelos profissionais, é que se constituem em aspecto crucial na criação ou determinação das possibilidades sobre como estudar, pesquisar e intervir.

Isso é que nos possibilita pensarmos em termos de uma contribuição teórica da PSC, sobretudo quando pensamos em fundamentos teóricos como os de: Martín-Baró (1996), com sua Psicologia Social da Libertação, que busca, por meio de estudos das circunstâncias concretas dos latino-americanos, dar resposta aos graves problemas de injustiça estrutural e desigualdades sociais; Paulo Freire (1980), com a noção de práxis libertadora, entendida como um processo humano constituído como unidade indissolúvel entre ação e reflexão sobre o mundo, realizada com a autêntica união dialógica entre os homens mediados pela realidade vivida, buscando-se superar os esquemas de acomodação e adaptação passiva à realidade e fomentando a integração com a inserção na realidade vivida; Vigotski (2008; 2009) e sua concepção acerca da constituição do sujeito, entendida como resultado de um processo de conversão do social no individual, sem que o indivíduo e sociedade mantenham entre si uma relação isomorfa, bem como pelos seus estudos pautados numa análise da realidade social, com ênfase no caráter histórico e reconhecimento do caráter ativo dos seres humanos como produtores da história.

Atividades realizadas pelo profissional numa semana típica de trabalho

As falas dos profissionais de Psicologia revelaram que eles realizam as seguintes atividades: acolhimento/tratamento psicológico; facilitação de grupos operativos e visitas domiciliares. A categoria acolhimento e atendimento psicológico denota que os profissionais de Psicologia realizavam, predominantemente, escuta psicológica, atendimento clínico, aconselhamento ou mesmo terapia psicológica. Mas sempre fizeram questão de pontuar que esse descumprimento dos marcos legais do SUAS (Brasil, 2009b) e das diretrizes para atuação dos profissionais de Psicologia (Conselho Federal de Psicologia, 2008) se justificava por haver uma demanda de que tinham que dar conta. Por mais que as condições infraestruturais do CRAS não fossem adequadas para tal. Tinham consciência de que essa não era forma ideal de atuação, mas acabavam fazendo diante de dificuldade para encaminhar usuários para outros serviços socioassistenciais. Dados semeIhantes, seguidos da mesma justificativa, foram encontrados no estudo de Fontenele (2008).

O depoimento da entrevistada cinco representa bem essa questão:

\footnotetext{
[...] as psicólogas do CRAS não é pra fazer atendimento clínico aqui no CRAS, só que a gente faz, porque realmente precisa. [...] eu sei que alivia, alivia muito e, às vezes, o problema não resolve, mas alivia, então a gente faz o atendimento [...] o atendimento clínico também.
} 
A partir das experiências relatadas pelos profissionais entrevistados, foi constatado que, nas facilitações dos grupos operativos e nas visitas domiciliares, o trabalho se desenvolve em outra perspectiva, interdisciplinar. Esses trabalham em parceria com o assistente social e outros técnicos do CRAS. Há, também, superação do foco no indivíduo. No entanto, essas atividades ficaram, respectivamente, em segundo e em terceiro planos. Percebe-se, dessa forma, necessidade de uma maior ênfase nas visitas domiciliares, realização de trabalhos com grupos de famílias ou seus representantes, e outras ações baseadas numa perspectiva psicossocial e que os aportes teóricos e metodológicos da PSC em muito poderiam dar suporte, fortalecendo a socialização, possibilitando a definição de projetos coletivos e desenvolvimento de uma consciência mais crítica por parte dos usuários.

Esse predomínio do acolhimento ou tratamento psicológico, nas atividades realizadas pelos profissionais de Psicologia no CRAS, também foi identificado por Andrade (2009), Andrade e Romagnoli (2010), Cruz (2009), Macedo e Dimenstein (2009) e Yamamoto e Oliveira (2010). Esses últimos autores destacam a importância de se pensar numa atuação que conjugue um posicionamento político mais crítico por parte dos psicólogos, com novos referenciais teóricos e técnicos. O que possibilita pensar-se tanto em quão discrepante se encontram as ações dos profissionais de Psicologia diante do idealizado para a atuação na Política Nacional de Assistência Social, quanto na importância das bases teóricas, ferramentas e técnicas, para subsidiar outro fazer psicossocial no contexto dos CRAS. São bases teóricas e metodológicas existentes na Psicologia, mas que não são enfatizadas nas grades curriculares, como éo caso da PSC e de outras versões de Psicologia.

Essa ênfase no acolhimento e tratamento psicológico é revelador acerca do quão individualizante continua sendo a atuação dos profissionais de Psicologia. Bock (2009) provoca uma reflexão acerca das limitações dessa atuação, o que, de acordo com essa autora, nos mostra como ainda estamos longe de colocar a Psicologia a serviço de quem dela necessita. Temos possibilidade de uma atuação bem mais abrangente, levando-se em conta o potencial de utilidade e de contribuição da Psicologia para a sociedade. Sobretudo quando se leva em consideração uma atuação pautada nas necessidades e experiências das populações oprimidas, que possibilite um ressignificar do papel dos sujeitos na direção da autonomia e uma participação destes nos processos políticos e na resolução das dificuldades vivenciadas por eles, em conformidade com uma perspectiva de efetivação dos direitos, modelo da Constituição em voga e das Políticas Públicas no Brasil.

Fernandes et al. (2008) consideram haver uma dificuldade, por parte dos profissionais de Psicologia que atuam nos CRAS, em exercer uma prática politizada embasada pelo compromisso social. E atribuem tal dificuldade a uma defasagem das instituições formadoras que ainda se pautam na formação do profissional clínico e liberal, o que diverge da característica necessária para a atuação nas Políticas Públicas, em especial, da Assistência Social, concepção essa compartilhada também por Ansara e Dantas (2010) e Cruz e Guareshi (2009).

Levando-se em consideração esse modelo de formação acadêmica, explica-se, em parte, um menor predomínio de referências dos profissionais de Psicologia à realização de atividades como visitas domiciliares ou outras que proporcionassem aos usuários acesso e conhecimento dos seus direitos, bem como a possibilidade de poderem compartilhar experiências e atuar junto à sua comunidade. Desenvolveriam, assim, vínculos afetivos e sociais, de forma a despertar o protagonismo social por meio de um processo de conscientização individual e grupal. Além de ajudarem os sujeitos a compreender sua realidade e libertar-se dos condicionamentos que a estrutura social lhes impõe, como orienta a PSC.

\section{Conclusões}

A partir da análise realizada, pode-se apontar que ações dos profissionais de Psicologia, 
no cotidiano dos CRAS, ainda se encontram notadamente ligadas a tecnologias oriundas de um modelo clínico tradicional, pautadas em perspectivas teóricas que fundamentam análise individualizante e descontextualizada. Em detrimento de ações orientadas numa análise das relações políticas, éticas, econômicas, sociais e de poder das realidades com as quais trabalham, identificando a dimensão subjetiva dessas. Buscam-se ações e políticas sociais voltadas à comunidade e aos grupos em condição de vulnerabilidade social e que contribuam para uma transformação social e melhoria na qualidade de vida da população focalizada.

A formação acadêmica é um dos aspectos que influenciam essa postura dos profissionais, pouco contribuindo para ações que efetivem os direitos dos usuários. Os desdobramentos de ações ligadas a tecnologias oriundas de um modelo clínico tradicional são intervenções cuja centralidade está no indivíduo, e não nas condições sociais dos usuários do CRAS, limitando-se a amenizar as sequelas decorrentes da condição de vulnerabilidade social dos usuários. Tal atuação pode ser caracterizada por aliviar o sofrimento psíquico, sem confrontá-lo com a realidade social que o gera. Essa postura dos profissionais de Psicologia, somada às limitações impostas pela própria política, possibilita questionar-se o impacto produzido por essas mudanças da atual Política Nacional de Assistência Social, por meio do SUAS, na condição de pobreza dos usuários, apenas possibilitando uma cidadania regulada.

Não é propósito do presente estudo responsabilizar os profissionais de Psicologia nem questionar a eficácia de suas ações, mas, sim, refletir acerca delas. Além disso, é de se chamar a atenção para a necessidade de serem revistas algumas atuações dos profissionais de Psicologia no âmbito das Políticas da Assistência Social, destacando-se a importância dos fundamentos teórico-metodológicos da PSC, como forma de se ampliar as possibilidades de contribuições para os usuários dessas políticas, pelo que ela oferece em termos de possibilidade de intervenção frente à realidade concreta dos sujeitos envolvidos.

Conhecer e refletir sobre a forma como os profissionais de Psicologia vêm atuando no CRAS pode ser entendido como eficaz estratégia para se problematizar ações que têm as tecnologias da clínica como modo de excelência, mesmo em espaços que demandam uma atuação num enfoque psicossocial, numa perspectiva de efetivação dos direitos dos usuários. Assim, é possível pensar-se em outras ações, por meio de um fazer psicossocial comprometido com a transformação social da realidade dos usuários das políticas da Assistência Social, embasado teórica e metodologicamente na PSC. Assim, superar-se-á, de uma vez por todas, a perspectiva estereotipada de Psicologia como ciência que cura problemas íntimos de "ricos", e que, quando lida com "pobres", se limita a aliviar o sofrimento psíquico.

Observações realizadas in loco poderiam fornecer dados mais precisos acerca das ações dos profissionais de Psicologia no CRAS. Tal limitação do estudo soma-se ao fato de esse debruçar-se sobre uma realidade específica e de se levar em consideração apenas a perspectiva do profissional de Psicologia, desconsiderando-se a perspectiva dos usuários do CRAS referente a essa atuação. Assim, sugere-se que estudos futuros contemplem esses aspectos e se adotem outras metodologias, de forma a se verificar o poder de generalização das constatações quanto às ações dos profissionais de Psicologia no CRAS. E que se contemplem as capacitações oferecidas pelos gestores das políticas ou, na falta delas, para os profissionais de Psicologia, e o que esses gestores esperam da atuação dos profissionais de Psicologia. 


\section{Orlando Júnior Viana Macêdo}

Doutor em Psicologia Social pela Universidade Federal da Paraíba, João Pessoa - PB. Brasil. E-mail: orlandojrvm@yahoo.com.br

\section{Maria de Fátima Pereira Alberto}

Doutora em Sociologia pela Universidade Federal de Pernambuco, Recife - PE. Brasil. Docente da Universidade Federal da Paraíba, João Pessoa - PB. Brasil.

E-mail: jfalberto@uol.com.br

\section{Denise Pereira dos Santos}

Mestre em Psicologia Social pela Universidade Federal da Paraíba, João Pessoa - PB. Brasil. E-mail: denyps@yahoo.com.br

\section{Gabriel Pereira de Souza}

Mestre em Psicologia Social pela Universidade Federal da Paraíba, João Pessoa - PB. Brasil. Docente da Faculdade do Vale do Ipojuca, Caruaru - PE. Brasil.

E-mail: gabrielpb2003@yahoo.com.br

\section{Vinicius Suares de Oliveira}

Graduação em Psicologia pela Universidade Federal da Paraíba, João Pessoa - PB. Brasil. E-mail: vinicius_suares@yahoo.com.br

\section{Endereço para envio de correspondência:}

Ambiente 25, Centro de Ciências Humanas, Letras e Artes, Universidade Federal da Paraíba. Cidade Universitária - Campus I. CEP: 58059-900. João Pessoa - PB. Brasil.

Recebido: 22/07/2013, $1^{\text {a }}$ Reformulação: 14/10/2014, Aprovado: 15/11/2014. 


\section{Referências}

Alberto, M. F. P., Almeida, D. R., Dória, L. C., Guedes, P. C., Sousa, T. R., \& França, W. L. P. (2008). O papel do psicólogo e das entidades junto a crianças e adolescentes em situação de risco. Psicologia Ciência e Profissão, 28(3), 558-573.

Alberto, M. F. P., Freire, M. L., Leite, F. M., \& Gouveia, C. N. N. A. (2014). As políticas públicas de assistência social e a atuação profissional dos(as) psicólogos(as). In I. F. de Oliveira, \& O. H. Yamamoto (Org.), Psicologia e políticas sociais: temas em debate (pp. 127-174). Belém: Ed. UFPA.

Andrade, L. F. (2009). O psicólogo no Centro de Referência da Assistência Social (CRAS) de Fortuna de Minas - MG: na trilha cartográfica dos territórios subjetivos. Dissertação de Mestrado, Pontifícia Universidade Católica de Minas Gerais, Belo Horizonte, MG.

Andrade, L. F., \& Romagnoli, R. C. (2010). O psicólogo no CRAS: uma cartografia dos territórios subjetivos1. Psicologia Ciência e Profissão, 30(3), 604-619.

Ansara, S., \& Dantas, B. S. A. (2010). Intervenções psicossociais na comunidade: desafios e práticas. Psicologia \& Sociedade, 22(1), 95-103.

Bardin, L. (2010). Análise de conteúdo. Lisboa: Edições 70.

Bock, A. M. B. (2009). Psicologia e sua ideologia: 40 anos de compromisso com as elites. In A. M. B. Bock (Org.), Psicologia e o compromisso social (pp. 15-28). São Paulo, SP: Cortez.

Brasil. Ministério do Desenvolvimento Social e Combate à Fome. (2009a). Orientações técnicas: Centro de Referência da Assistência Social. Brasília, DF: Autor.

(2012). Orientações técnicas sobre o PAIF: trabalho social com famílias do Serviço de Proteção e Atendimento Integral a Família - PAIF. Brasília, DF: Autor.

(2009b). Tipificação nacional de serviços socioassistenciais. Brasília, DF: Autor.

(2004). Política Nacional de Assistência Social - PNAS. Brasília, DF: Autor.
Conselho Federal de Psicologia (2008). Referências Técnicas para atuação do(a) psicólogo(a) no CRAS/ SUAS. Brasília, DF: autor.

Conselho Nacional de Saúde (1996). Resolução $\mathrm{n}^{\circ} 196$, de 10 de outubro de 1996. [aprovar diretrizes e normas regulamentadoras de pesquisas envolvendo seres humanos]. Diário Oficial da União. 16 out. 1996.

Cruz, J. M. O. (2009). Práticas psicológicas em Centro de Referência da Assistência Social. Psicologia em Foco, 2(1), 11-27. Recuperado em 15 de junho de 2013, de http://linux.alfamaweb.com.br/sgw/ downloads/161_063502_ARTIGO2 PraticaspsicologicasemCRAS.pdf

Cruz, L. R., \& Guareshi, N. M. F. (2009). A constituição da assistência social como política pública: interrogações à psicologia. In L. R. Cruz, \& N. Guareshi, (Orgs.), Políticas públicas e assistência social: diálogos com as práticas psicológicas (pp. 13-38). Petrópolis, RJ: Vozes.

Fernandes, A. M. D., Joca, E. M., Alencar, L., \& Albuquerque, R. (2008). Centro de Referência da Assistência Social (CRAS) na cidade de João Pessoa: diálogos entre a psicologia e as políticas públicas (Relatório de pesquisa do PIBIC/ UFPB - CNPq/2008). João Pessoa, PB, Universidade Federal da Paraíba.

Fontenele, A. F. G. T. (2008). Psicologia e Sistema Único da Assistência Social - SUAS: estudo sobre a atuação dos psicólogos nos Centros de Referência da Assistência Social - CRAS. Dissertação de Mestrado, Departamento de Psicologia, Universidade Federal do Ceará, Fortaleza, CE.

Fontanella, B. J. B., Ricas, J., \& Turato, E. R. (2008). Amostragem por saturação em pesquisa qualitativa. Caderno de Saúde Pública, 24(1),17-27.

Freitas, M. F. Q. (1998). Inserção na comunidade e análise de necessidades: reflexões sobre a prática do psicólogo. Psicologia: Reflexão e Crítica, 11(1), 175-189.

Freire, P. (1980). Conscientização: teoria e prática da libertação: uma introdução ao pensamento de Paulo Freire. São Paulo, SP: Moraes.

Góis, C. W. L. (2008). Saúde comunitária: pensar e fazer. Fortaleza, CE: Hucitec. 
Lima, M. C. F. (2012). "A Beleza de Ser um Eterno Aprendiz": uma palavra sobre a formação do psicólogo. In A. M. Jacó-Vilela; A. C. Cerezzo, \& H. B. C. Rodrigues (Orgs.), Clio Psyché hoje: fazeres e dizeres psi na história do Brasil (pp. 3-13). Rio de Janeiro, RJ: Relume Dumará.

Macedo, J. P., \& Dimenstein, M. (2012). O trabalho dos psicólogos nas políticas sociais no Brasil. Avances en Psicología Latinoamericana, 30(1), 182-192.

Macedo, J. P., \& Dimenstein, M. (2009). Psicologia e a produção do cuidado no campo do bem-estar social. Psicologia \& Sociedade, 21(3), 293-300.

Macedo, J. P. S. (2007). O psicólogo no campo de bem-estar: cartografias de práticas na assistência social e saúde. Dissertação de Mestrado, Programa de Pós-Graduação em Psicologia, Universidade Federal do Rio Grande do Norte, Natal, RN.

Macêdo, O. J. V. (2014). Atuação de profissionais depsicologianaspolíticaspúblicas de proteção social no âmbito da assistência social. Tese de Doutorado, Programa de Pós-Graduação em Psicologia Social, Universidade Federal da Paraíba, João Pessoa, PB.

Martín-Baró, I. (1996). O papel do psicólogo. Estudos de Psicologia, 2, 7-27.

Mota, S. T., \& Goto, T. A. (2009). Plantão psicológico no CRAS em Poços de Caldas. Fractal: Revista de Psicologia, 21(3), 521-530.

Nepomuceno, L. B., Ximenes, V. M., Cidade, E. C., Mendonça, F. W. O., \& Soares, C. A. (2008). Por uma psicologia comunitária como práxis de libertação. Psico, 39, 456-464. Recuperado em 1 de maio de 2013, de: http://revistaseletronicas.pucrs.br/ojs/index. php/revistapsico/article/viewFile/3532/3836

Nery, V. B. (2009). O Trabalho dos assistentes sociais e psicólogos na política de assistência social: saberes e direitos em questão. Tese de Doutorado, Serviço Social, Pontifícia Universidade de São Paulo, São Paulo, SP.

Netto, J. P (2011). Capitalismo monopolista e serviço social. São Paulo, SP: Cortez.

Oliveira, I. F., Dantas, C. M. B., Solon, A. F. A. C., \& Amorim, K, M. O. (2011). A prática psicológica na proteção social básica do SUAS. Psicologia \& Sociedade, 23(n. spe.), 140-149.
Raichelis, R. (2010). Intervenção profissional do assistente social e as condições de trabalho no SUAS. Serviço Social e Sociedade, (104), 750-772.

Ribeiro, A. B. (2010). O psicólogo na proteção social especial: atuação junto às vitimas de violação de direitos no CREAS. Dissertação de Mestrado não publicada, Universidade Federal do Rio Grande do Norte, Natal, RN.

Silva, C. S., Silva, I. R., Brustolin, M. L., \& Pessini, M. A. (2011). Algumas considerações sobre as influências do assistencialismo nas práticas psicológicas realizadas nos Centros de Referência de Assistência Social (CRAS). Akrópolis Umuarama, 19(1), 3-13.

Silva, M. V. O. (2011). V Seminário Nacional de Psicologia e Políticas Públicas: subjetividade, cidadania e políticas públicas (Relatório). Brasília, DF: Conselho Federal de Psicologia.

Soares, J. N., Susin, L., \& Warpechowski, M. B. (2009). A clínica ampliada na assistência social. In L. R. Cruz \& N. Guareshi, (Orgs), Políticas públicas e assistência social: diálogos com as práticas psicológicas (pp. 151-161). Petrópolis, RJ: Vozes.

Vigotski, L. S. (2008). Pensamento e linguagem. São Paulo, SP: Martins Fontes.

Vigotski, L. S. (2009). A construção do pensamento e da linguagem (P. Bezerra, trad.). São Paulo, SP: WMF Martins Fontes. (Original publicado em 1934).

Ximenes, V. M., Paula, L. R. C., \& Barros, J. P. P. (2009). Psicologia comunitária e política de assistência social: diálogos sobre atuações em comunidades. Psicologia Ciência e Profissão, 29(4), 686-699.

Yamamoto, O. H. (2012). 50 anos de profissão: responsabilidade social ou projeto ético-político? Psicologia: Ciência e Profissão, 32(n esp.), 6-17.

Yamamoto, O.H. (2007). Políticas sociais, 'terceiro setor' e 'compromisso social': perspectivas e limites do trabalho do Psicólogo. Psicologia \& Sociedade, 19(1), 30-37.

Yamamoto, O. H., \& Oliveira, I. F. (2010). Política social e psicologia: uma trajetória de 25 anos. Psicologia: Teoria e Pesquisa, 26(n esp), 9-24. 